\title{
Teoría de la activación digital. Propuesta teórico-metodológica de las prácticas comunicativas de los movimientos sociales en red
}

\section{Digital activation theory. Theoretical-methodological proposal of the communicative practices of networked social movements}

Recibido: 01/08/2019

Aceptado: 30/09/2019

Publicado: 05/12/2019
Óscar Bustamante Farías

oscar.bustamantef@mayor.cl

Universidad Mayor (Chile)

Resumen: El artículo formaliza una propuesta teórico-metodológica de las prácticas comunicativas de los movimientos sociales en red como nuevo ciclo de la acción colectiva. La activación digital se propone como un objeto de estudio emergente e interdisciplinario, que consta de contextos y dimensiones, que puede ser estudiado a la luz de la "hermenéutica profunda" y que representa un aporte al subcampo de la comunicación política.

Palabras clave: Movimientos sociales en red, Activación digital, Comunicación política.

Abstract: The article formalizes a theoretical-methodological proposal of the communicative practices of networked social movements as a new cycle of collective action. Digital activation is proposed as an emergent and interdisciplinary object of study, which consists of contexts and dimensions that can be studied under the light of "deep hermeneutics", and that represents a contribution to the sub-field of political communication. 
Key words: Networked social movements, Digital activation, Political communication.

\section{Introducción}

Lo que presentamos a continuación tiene como antecedente directo la investigación desarrollada en el marco del doctorado en Estudios Científico-Sociales, del ITESO de Guadalajara (México), titulada "Mediatización de la protesta: la activación digital como modalidad de comunicación política" (Bustamante 2014), que tomó como objeto de referencia al movimiento estudiantil chileno del 2011; año en que, vale la pena recordar, fue testigo de un nuevo ciclo de movimientos sociales en la red (Castells, 2012) en varios países del mundo.

Nuestro objetivo ahora es ofrecer la formalización de una propuesta teórico-metodológica que abone al campo de la comunicación, particularmente al subcampo de la comunicación política, en torno a un objeto de estudio emergente que nació al alero de la literatura sobre movimientos sociales y activismo digital, pero que se desplazó (por méritos que explicaremos en el texto) al ámbito comunicacional.

En el segundo apartado del presente artículo, presentamos los principales hallazgos referidos al "estado del arte" sobre movimientos sociales y activismo digital a partir del cual emergió un primer marco heurístico y, de manera complementaria, la definición de "activación digital". Esta definición se desmarca de la de "activismo digital" (Joyce, 2010), dado su carácter restrictivo e internalista, y se despliega en diferentes dimensiones de la acción colectiva.

Una tercera sección está dedicada a la construcción de nuestro objeto de estudio: la activación digital, sus contextos y dimensiones. Dichos contextos refieren a tres "niveles de sentido" en los que se inscriben las prácticas comunicativas (los malestares de la globalización, la mediatización de la protesta y la apropiación de las redes multimedia globales) en tanto que las dimensiones remiten a modalidades de la apropiación de dichas prácticas: "tecno-lógica", "ideo-lógica" y "socio-lógica". Contextos y dimensiones, además, enmarcadas en coordenadas espacio-temporales precisas. 
La cuarta sección es metodológica y refiere a la propuesta de la "hermenéutica profunda de la activación digital" en tanto perspectiva comunicacional. Esta propuesta corresponde a una adaptación de un modelo de Thompson (2002) a las necesidades de la comunicación digital interactiva (Scolari, 2008) dentro de los diferentes tipos de análisis que establece. Un primer análisis, por ejemplo, es "sociohistórico" y remite a dos de los tres contextos de la activación digital: el contexto de los malestares y el de la protesta. Un segundo análisis es el de la "apropiación” y comprende las tres dimensiones de la activación digital señaladas. Un tercer análisis es respecto a la "reflexividad", tanto del investigador como de los sujetos, desembocando en una espiral (re)interpretativa.

Finalizamos el texto, ya en la quinta sección, con un balance de lo que, a nuestro juicio, es el aporte que la activación digital puede hacer al subcampo de la comunicación política a partir de la "inversión" de sus términos o, para decirlo de otro modo, a partir de cómo consideramos pertinente y relevante inscribir este objeto de estudio en el campo comunicacional. Es también propósito de este apartado relevar el carácter interdisciplinario de nuestra propuesta, derivado del programa académico en que se originó, y esperar que sus planteamientos den origen a nuevas investigaciones. Pues, como señaló hace años Kurt Lewin, "no hay nada más práctico que una buena teoría".

\section{Del activismo a la "activación digital". Estado del arte y emergencia de un nuevo concepto}

En nuestro "estado del arte" trabajamos sobre un corpus de cerca de 90 artículos relativos a la literatura sobre movimientos sociales y activismo digital. Derivado de su análisis, inferimos tres contextos de la activación digital, que desarrollaremos en el próximo apartado, y que operan como "niveles de sentido" de las prácticas comunicativas. Estos contextos los enunciamos: los malestares de la globalización, la mediatización de la protesta y la apropiación de las redes multimedia globales.

Del contexto de la apropiación de las redes digitales, trabajamos sobre cinco dimensiones: tecnológica, política, organizacional, identitaria y lo que denominamos "poder de la comunicación" para referir a su impacto en el espacio 
y la esfera pública a través de diversas tácticas y estrategias mediáticas ${ }^{1}$. Así, por ejemplo, en la dimensión tecnológica un tema recurrente es la brecha digital. Para el caso de América Latina, así como para otras regiones del mundo, esta dimensión es relevante porque se suma a brechas estructurales que se acaban expresando en una incorporación asimétrica y desigual de los usuarios a la información y el conocimiento (ALAI, 2001, 2005; Lago \& Marotias, 2007; Mari Sáez, 2007).

Otra cuestión asociada a la dimensión tecnológica se relaciona con las características de la Internet como "hipermedio". Para Scolari (2008) estas son cinco: digitalización, reticularidad, interactividad, hipertextualidad y multimedialidad. Todas estas dan forma a una nueva ecología de medios, a nuevas modalidades de comunicación y de interacción social. Aunque muchos han reparado en el valor de la interactividad, Castells (2009) la llama "autocomunicación masiva" ${ }^{2}$ y su potencial para los movimientos es convertirlos en productores de contenidos que les permitan sortear las barreras de acceso de los medios de difusión y alcanzar la esfera pública.

Todas estas propiedades tecnológicas desembocan en el espíritu libertario, innovador y altruista que está en la génesis de la Internet (Castells, 2003), cuya emergencia coincidió con la redefinición de la política y de los propios movimientos sociales (Jensen, 2005). Aquellos valores que Himanen (2002) denomina "Nética" y que encarnan en la figura del "hacker": persona que (sin tratarse necesariamente de un experto informático) dispone de una concepción del trabajo, del dinero y del placer que rompe con la lógica mercantil.

En cuanto a la dimensión política, para Bennett (2003), los aportes fundamentales del activismo digital se pueden resumir en las siguientes tendencias: $a$ )

1. Estas dimensiones, además, tuvieron su correlato con la literatura sobre movimientos sociales. Así, por ejemplo, la dimensión política lo tuvo con las "teorías de proceso político" (Della Porta \& Diani, 2006; McAdam, McCarthy \& Zald, 1999; Rodríguez Arechavaleta, 2010), la dimensión organizacional lo tuvo con las "estructuras de participación" (Tarrow, 2004; Laraña, 1999; Della Porta \& Diani, 2006) y la dimensión simbólica lo tuvo con lo referido a los "nuevos movimientos sociales" (Mardones, 1996) y los marcos de acción colectiva (Chihu Amparán, 2006; Snow, Rochford, Worden \& Benford, 2006).

2. No es el primero en acuñar un nombre para la comunicación "muchos a muchos" de las redes digitales. Previamente ya se ha hablado de "new media", "multimedia", "comunicación digital", "comunicación interactiva", "cibermedios", "comunicación participativa", "comunicación 2.0", "cibercomunicación” o "e-Comunicación". 
promocionar la creación de campañas permanentes con objetivos cambiantes; b) reducir la influencia de la ideología en la participación en los movimientos sociales (Kavada, 2006); c) posibilitar luchas ideológicas en el ciberespacio (Leetoy, 2004); d) sustentar estrategias de comunicación política, de organización y movilización en modos que replican, reemplazan o complementan a los medios y los movimientos tradicionales (Jensen, 2005); e) permitir la emergencia de un sujeto político heterogéneo (Lago \& Jara, 2001; Barandiaran, 2003) y f) posibilitar el tránsito desde el espacio público a la "pantalla pública" (De Lucca \& Peeples, 2002).

Garrett (2006), basándose en los ejemplos de los movimientos altermundistas, plantea que las redes digitales pueden contribuir a un ambiente de mayor acción colectiva. Primero, el bajo costo del activismo digital permitiría un mayor número de personas para sustentar un movimiento. Segundo, la posibilidad de coordinación global significa que los activistas puedan funcionar como parte de una extensa red de acción colectiva compuesta por varias protestas locales (pp. 13-14).

Un concepto en esta dirección es el de política viral. Se trata de una nueva acción política que combina el espacio material y digital de la protesta en torno a acciones específicas que tienen la capacidad de producir "esferas públicas transitorias" (Acosta, 2009; Arditi, 2010). Se podría, de hecho, estar asistiendo a un "giro comunicativo" en el cual los movimientos sociales devienen en "medios de comunicación" (Valderrama, 2010).

Las características apuntadas bien pueden resumirse en lo señalado en los "movimientos sociales en red". Primero, al ser básicamente movimientos de "opinión pública", no son canalizados en acción política instrumental ni cooptados por partidos políticos, si bien son políticos en un sentido fundamental: al proponer y practicar una democracia directa y participativa y al plantear la autonomía del sujeto con respecto a las instituciones. Segundo, son movimientos altamente "reflexivos", lo cual se manifiesta en sus procesos de deliberación en asambleas y en los foros por Internet. Tercero, no son movimientos programáticos a menos que dispongan de una exigencia concreta de "derrocar al dictador". Estos detonan, más bien, múltiples malestares provenientes de la ciudadanía. Debido a esto, los movimientos no formalizan ninguna organización o liderazgo porque su consenso, su fraternidad, depende de una deliberación y protesta $a d$ hoc, no de la realización de un programa construido sobre objetivos específicos. 
En la dimensión organizativa del activismo digital, la propiedad de red distribuida de Internet (Castells, 2003) y su correlato con la estructura orgánica de los movimientos sociales es una fuente de ventajas en varios sentidos. Ya sea para la comunicación, intercambio y coordinación entre activistas y organizaciones (Bennett, 2003; Monasterios, 2003); ya sea como proceso organizacional en sí mismo (Kavada, 2006); ya sea incrementando las ventajas estratégicas de organizaciones con escasos recursos dentro de los movimientos (Bennett, 2003); ya sea para desarrollar nuevas formas de acción, gestión y participación (De Moraes, 2001); ya sea para recuperar el valor de la cooperación, originario del "espíritu de la Internet" (Rheingold, 2004; Himanen, 2002); ya sea para establecer nuevas territorialidades a partir de la articulación local/global (Lago, 2006); ya sea para sustentar el "ciclo internacional de luchas" (Hardt \& Negri, 2004). O ya sea, en términos estratégicos, para el desarrollo de una "desobediencia civil electrónica" (CAE, 2001), una "infowar" (Baldi, 2000; Crilley, 2001), una "Netwar" (Arquilla \& Ronfeldt, 2001) o una política viral (Acosta, 2009; Arditi, 2010).

Lo fundamental, en todo caso, es la configuración de los nuevos conflictos contemporáneos en red. Redes sociales que, si bien son de larga data en la historia (Arquilla \& Ronfeldt, 2001), se ven potenciadas por la reticularidad de Internet que las favorece frente a las estructuras institucionales jerárquicas dominantes en la modernidad y derivadas de su racionalización.

En la dimensión identitaria, entendida como el principio mediante el cual el actor social se define a sí mismo y en nombre del cual actúa (Ramírez, 2006), la literatura consigna diferentes articulaciones con la activación digital. Para Monasterios (2001), y en relación a movimientos indígenas latinoamericanos, la Internet provee un medio de representación que tiende a la identificación de los sujetos, la producción de imaginarios y una apuesta por la interculturalidad (Monasterios, 2003).

La comunicación digital, asimismo, posibilita la formación de "identidades trasnacionales" basadas en valores solidarios y de confianza (Monasterios, 2003; Kavada, 2006) y derivada de una creciente politización de la vida cotidiana (Kahn \& Kellner, 2004). La construcción de un "nosotros" internacional, por lo tanto, se estaría convirtiendo en un rasgo cada vez más reconocible en los movimientos sociales del siglo XXI, si bien resta evidencia para hablar de un fenómeno asentado (Ramírez, 2006; Tilly, 2005). 
Arribamos, así, a nuestra última dimensión: el poder de la comunicación. En primer lugar, la política y los conflictos actuales se desarrollan en las redes multimedia globales donde se disputan las mentes humanas y los marcos interpretativos. De un lado, actores poderosos que ejercen cuatro formas de poder y dominación (poder de "conectar en red", el poder "de la red", el poder "en red" y el poder de "crear redes") y que los convierte en sus "programadores". Dado el volumen, alcance y tipos de recursos que movilizan, estos poderes son incomparables con las formas de contrapoder. De un lado, la "reprogramación" de las redes que ejercen los usuarios, aquella "premisa generativa" inscrita en la dialéctica de la interactividad. De otro lado, el "cambio cultural" al que aspiran los movimientos sociales y, finalmente, el cambio que movilizan las "políticas insurgentes", procesos en discontinuidad con la lógica incorporada en las instituciones políticas.

Todas estas resistencias se encuentran conformando reconfiguraciones de "esferas y espacios públicos" donde las ideas y los valores se producen, se comparten, se respaldan, se combaten y se transforman. El activismo digital, entonces, se destaca como una apropiación del "espacio de flujos" para la construcción de circuitos en las redes multimedia globales (Lago \& Jara, 2001; Fleischman, 2004; Lago \& Marotias, 2007; Mari Sáez y Sierra, 2008). Y en este propósito, resultan fundamentales las tácticas de construcción, experimentación y politización de lo técnico (Barandiaran, 2003): hacktivismo, hackmeeting y hacklabs, servidores autónomos y telemática antagonista, mediactivismo, artivismo, infowar (Baldi, 2000; Crilley, 2001; Candón Mena, 2010; Pasquinelli, 2002).

Presentada esta resumida versión de las dimensiones del activismo digital, queremos detenernos en las últimas tres evidencias que nos arrojó la revisión bibliográfica: primero, en el nuevo ciclo de los "movimientos sociales en red" (Castells, 2012), las prácticas comunicativas del activismo digital están cobrando una importancia inédita, cual es la de estar participando, ya no orbitando en la periferia, de los sistemas de comunicación pública. Lo anterior, gracias al proceso originario de "integración por digitalización" que proveen las redes multimedia globales y que se puede entender como un proceso simultáneo de convergencia/divergencia ${ }^{3}$.

3. Esto es, la convergencia tecnológica que posibilita la convivencia de al menos tres subsistemas de comunicación: medios masivos, medios locales o alternativos y medios digitales y, en contrapartida, la divergencia de actores que políticamente difieren en sus propósitos y que disputan el poder en el nuevo ecosistema mediático. 
Una segunda evidencia que encontramos fueron (del lado de la literatura sobre movimientos sociales) las prácticas comunicativas subordinadas a otras dimensiones de la acción colectiva que se consideran más decisivas, como las políticas u organizacionales, pero también (del lado del activismo digital) a las prácticas comunicativas acotadas dentro de una definición restrictiva e internalista. En ambos casos, la comunicación aparece oscurecida por la luz que se arroja sobre otros fenómenos y procesos.

Una tercera evidencia fue que, con el propósito de delimitar un objeto de estudio, Joyce (2010) concibe el activismo digital como "aquellas prácticas comunicativas para todo tipo de causas sociopolíticas dentro del ámbito del ciberespacio". Una definición caracterizada por criterios de exhaustividad y exclusividad ${ }^{4}$. Para nosotros, sin embargo, esta definición es restrictiva e internalista. Restrictiva, por cuanto creemos que los movimientos sociales arraigan en malestares de naturaleza biopolítica ${ }^{5}$, es decir, que cubren todos los ámbitos de la vida y las relaciones sociales. Internalista, por cuanto las prácticas comunicativas del activismo digital no se restringen al ciberespacio y al contexto de la interacción mediática, sino que se hayan articuladas con el espacio offline de la protesta y la vida cotidiana.

Presentamos, por lo tanto, nuestra definición de activación digital: una modalidad de prácticas comunicativas por las redes multimedia globales en el marco de los movimientos sociales e insurgencias contemporáneas, las cuales se encuentran articuladas con las prácticas performativas de la protesta y la vida cotidiana, en función de los malestares y los fines que movilizan a sus participantes. A partir de esta definición, se comienza a configurar nuestro objeto de estudio.

4. La exhaustividad de las múltiples causas sociopolíticas y la exclusividad de las prácticas comunicativas dentro del ciberespacio.

5. Para Hardt \& Negri (2009), el concepto de biopolítica, tomado de Foucault, es doble: no únicamente representa un tipo de poder sino también una producción de subjetividad, ya sea por el modo de acumulación capitalista, orientado a la explotación de las relaciones sociales, o ya sea por las expresiones de la multitud, orientada a la producción de lo "común". Ambas formas de producción biopolítica (la del capital y la de la multitud) comparten el prefijo "bio" en la medida que afectan a toda la vida social, aunque de manera muy diferente (Hardt \& Negri, 2004). 


\section{Contextos y dimensiones de la activación digital: construcción del ob- jeto de estudio}

En la figura 1 presentamos una representación de la activación digital. Los tres contextos de la activación digital constituyen un "flujo en tres pasos" (Jensen, 2010), a través del cual se desarrolla un proceso de transformación desde figuras de subjetividad agraviadas a figuras de subjetividad potenciadas por la mediación del movimiento social. Los contextos de la activación digital, como mencionamos en el apartado anterior, corresponden a niveles de sentido en los que se inscriben las prácticas comunicativas y constituyen tanto un marco heurístico como la proposición de una tendencia ${ }^{6}$ de la acción política.

Figura 1: Activación digital: contextos y dimensiones.

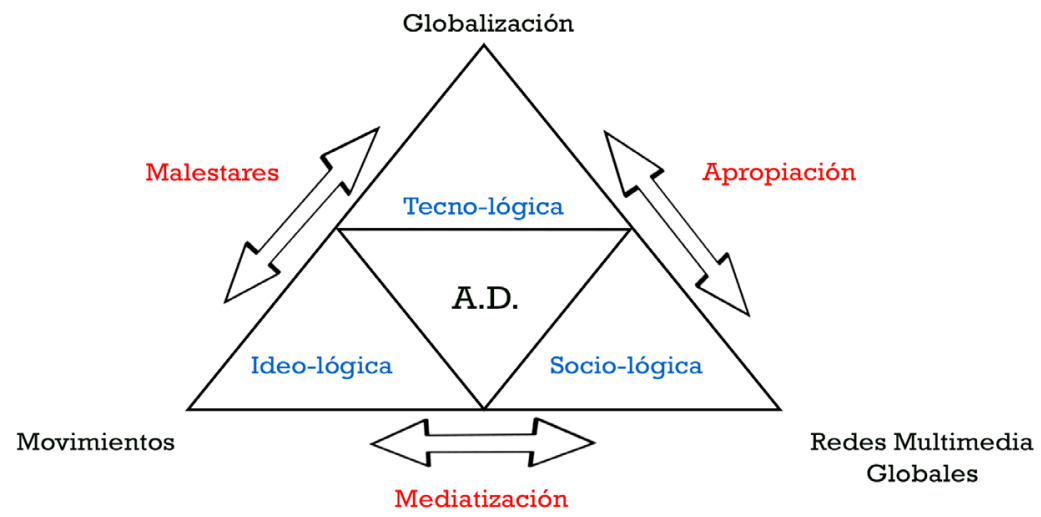

Fuente: Elaboración propia.

Comencemos por el contexto de los malestares. Los malestares sociales son una condición propia de la modernidad y para nosotros constituyen tendencias cualitativas. Metodológicamente, el malestar social es un tipo de concepto

6. “Para el análisis del capitalismo industrial en el siglo XIX, Marx se habría inspirado en la noción de tendencia, según la cual el número es importante pero la clave consiste en captar el rumbo para predecir qué semillas prosperarán y cuáles se agostarán. Y su gran mérito consistió en interpretar la tendencia y realizar la proyección de que el capital, entonces todavía en su infancia, iba a convertirse en una forma social completa" (Hardt \& Negri, 2004, 173-174). 
sensible, no definitivo ${ }^{7}$ (Jensen, 2013). Del análisis de los "malestares de la globalización" (realizado en el "estado del arte" y dada su naturaleza biopolítica) proponemos que el sistema actual (neoliberalismo) produce las siguientes figuras de subjetividad, en una matriz de relaciones complejas:

- Sujeto endeudado: aquella subjetividad estructuralmente inscrita sobre un principio de desigualdad en la distribución de los ingresos y sometida a cadenas de endeudamiento. Vive el temor a la exclusión y manifiesta malestares en su condición de consumidor.

- Sujeto mediatizado: una subjetividad que participa de un amplio ecosistema de medios y prácticas comunicativas. Es consumidor de tecnologías de comunicación y crecientemente productor de contenidos (prosumidor), aunque negocia en su condición de audiencia con información fragmentaria, efímera, irrelevante y presentista. Sufre de un exceso de información, viene manifestando un creciente malestar con la falta de diversidad en los contenidos de los medios de difusión masiva y su relación social con la política es a través de la "política mediática"8 (Castells, 2009).

- Sujeto securizado: es objeto de la producción de miedos e inseguridades como condiciones de la sociabilidad. Es objeto también de la vigilancia tanto corporal como de sus datos y de políticas de seguridad ciudadana según criterios expertos. Manifiesta malestares hacia las lógicas del desarrollo urbano, la privatización de los espacios públicos y el declive de las instancias de producción de capital social.

- Sujeto representado: una subjetividad cuya participación democrática se circunscribe al evento electoral y la experiencia participativa indi-

7. Un concepto definitivo, explica Jensen (2013), refiere a lo que es común a una clase de objetos con la ayuda de una definición clara en términos de atributos. Aunque estos conceptos pueden proveer instrumentos precisos y eficientes de análisis, son insuficientemente sensibles para los casos empíricos y sus contextos. Un concepto sensible, en cambio, otorga un sentido general de referencia y de guía a su aproximación empírica, permite establecer relaciones cercanas con el mundo social.

8. La "política mediática" es un tipo de relación con la política a través del entorno mediático, de preferencia la televisión y, más recientemente, los medios digitales. Dicha relación se organiza según las lógicas mediáticas y dispone de una serie de tácticas (spinning, campañas y escándalo) orientadas a una estrategia clara: la personalización de la política. La política mediática tiende a la "espectacularización de todo" y, citando a McLuhan, a asumir que "el medio es el mensaje". Como veremos más adelante, la política mediática también produce una "partición de lo sensible" (Rancière, 1996) en el régimen perceptivo de una colectividad.

ISSN: 2304-2265 
recta a través del espectáculo de la política mediática. para este sujeto, la representación ha pasado de ser un vehículo a un obstáculo de la democracia, de ahí su desafección emotiva. Manifiesta malestares hacia el sistema político y reclama una mayor entrega de poder a los ciudadanos.

Estas figuras de la subjetividad no son absolutas, sino más bien perfiles de los diversos malestares derivados del sistema en el mundo. Pero, además, al estar repartidas en una diversidad de prácticas sociales y formas de la experiencia, estas figuras de subjetividad confluyen en la constitución de un sujeto político, a partir del consenso como principio de orden.

En cuanto al segundo contexto (la mediatización de la protesta o de un nuevo ciclo de "movimientos sociales en red") proponemos como su rasgo distintivo lo ya señalado: actualmente, los movimientos sociales participan de los sistemas de comunicación pública, ya no los orbitan como en ciclos previos de su emergencia en el espacio público. Y agregamos algo más: actualmente los movimientos sociales expresan una tendencia de "internacionalización por mediatización", a diferencia de antes cuando se articulaban orgánicamente entre ellos, mediante dinámicas como el "efecto demostración" o la viralización de las causas por las redes multimedia globales 9 .

El proceso señalado, ciertamente, se inscribe en uno más largo de mediatización de la cultura y la sociedad. De hecho (y al igual que la globalización capitalista, la individualización y los movimientos sociales) la mediatización forma parte de la evolución y experiencia de la modernidad. Pues, como señala Berman (2004),

la vorágine de la vida moderna ha sido alimentada por muchas fuentes: (entre ellos) los sistemas de comunicación de masas, de desarrollo dinámico, que envuelven y unen a las sociedades y pueblos más diversos (pp. 1-2).

9. En nuestra investigación, distinguimos entre "movimientos sociales nómadas" y "movimientos sociales sedentarios". Mientras entre los primeros figuran, por ejemplo, los movimientos altermundistas o "antiglobalización" que se articulaban en torno a eventos como el Foro Social Mundial de Porto Alegre, en el segundo grupo incluimos a toda esa serie de movimientos locales que, sin disponer de una articulación expresa y menos aún una orgánica, se conocían entre sí mediáticamente. Este rasgo, por cierto, va aunado a otros rasgos de los "movimientos sociales en red", tales como su alta emotividad y la ausencia de líderes. 
Tres cuestiones nos interesan enfatizar a continuación. Primero: la dimensión simbólica, dentro de la cual se inscribe la mediatización, ha venido cobrando mayor relevancia en las teorías sobre movimientos sociales, desde las formulaciones de la "Escuela de Chicago" hasta convertirse en parte del "conflicto central" en las sociedades complejas, según lo consigna la literatura sobre nuevos movimientos sociales (Mardones, 1996; Melucci, 1999), y en dimensión constituyente de la acción política en la actual globalización neoliberal. Segundo: asumir la mediatización de la protesta como tendencia, implica poner las prácticas comunicativas de los movimientos sociales al centro del análisis, pero en directa y densa relación con las otras dimensiones constituyentes (estructurales, organizacionales y políticas) a las que media. Tercero: asumir la mediatización implica abrirse a analizar cómo las lógicas y las culturas mediáticas son utilizadas como recursos para la resistencia. Tal es el caso de la activación digital.

Respecto al tercer contexto de la activación digital, sólo nos resta decir que por "apropiación de las redes multimedia globales" entendemos los siguientes rasgos de las prácticas comunicativas: a) "maneras de hacer", tácticas de consumo, aquellos movimientos "en el interior del campo de visión del enemigo" y dentro del espacio controlado por este (De Certeau, 2000); b) "sentido" de la acción colectiva, en cuanto proceso de aprendizaje (ALAI, 2001; Mari Sáez, 2007); y c) "usos significativos" de las tecnologías que actúan como condición para el logro de resultados (Sunkel, Trucco \& Möller, 2011).

Pasamos ahora al análisis de las dimensiones de la activación digital. Las dimensiones son constitutivas de las prácticas comunicativas del proceso de apropiación de las redes digitales. Basados en las lógicas de resistencia que le imprimen los sujetos a la acción colectiva, definimos tres: "tecno-lógica", "ideo-lógica" y "socio-lógica". Todas ellas enmarcadas en coordenadas espacio-temporales y relaciones de poder que, en conjunto, constituyen un poder de la comunicación.

El poder tecno-lógico, por ejemplo, lo entendemos como aquella capacidad de apropiación de los recursos ofrecidos por las redes multimedia globales (reticularidad y digitalización que posibilitan la formación del ecosistema mediático, fundamentalmente) para el desarrollo de "usos sociales" (Lull, 1980) dentro del marco de la "dialéctica de la interactividad" (Scolari, 2008). Proponemos que la tecno-lógica subvierte la lógica mercantil de la producción 
cultural dominante, con el desarrollo de un modo de producción al margen del interés en el lucro y que se orienta por usos sociales basados en las culturas políticas y los fines del movimiento. Es decir, aquello que Alonso (2012) denomina la acción de los movimientos sociales "por fuera del capital".

Aunque lo detallaremos en la próxima sección, dedicado a la propuesta metodológica de la activación digital, señalemos que en esta dimensión nos interesa el reconocimiento del movimiento social como nodo de comunicación, su modo de producción cultural, el mapa de la activación digital, la red de activación digital que establece y los usos sociales que desarrolla.

El poder ideo-lógico, por su parte, refiere a la producción de una narrativa política y una cultura visual propia que configuran una "partición de lo sensible", una ruptura en el régimen perceptual hegemonizado por la lógica espectacular de la política mediática en tanto manifestación de un orden policial, según Rancière (1996). Esta narrativa lo que hace es subvertir la lógica de la política mediática y pasar desde una relación comunicativa en donde "el medio es el mensaje" a otra en donde "el mensaje es el mensaje". Y al hacerlo, incide sobre el desprestigio del sistema político y el sentido de la democracia. Aquello que Alonso (2012) denomina la acción de los movimientos sociales "por fuera del Estado".

En esta dimensión nos interesa la definición de un ciclo de activación digital, de determinados actores de la narrativa política y sus relaciones, de su eventual inserción dentro de una comunidad global de resistencias, de la transmedialidad de sus contenidos y de la estética que la caracteriza.

El poder socio-lógico de la activación digital, por último, permite al movimiento social, como nunca antes en su historia de emergencias, la participación e incidencia en los sistemas de comunicación pública. Esta novedad le permite el desarrollo de tácticas y circuitos de comunicación, la producción de esferas públicas transitorias (Acosta, 2009) y la construcción de una agenda de poder (Dorantes, 2008). El análisis de la dimensión sociológica, por lo tanto, nos permite visualizar la resonancia del movimiento social en la sociedad donde se manifiesta o aquello que Castells (2009) llama su "reprogramación". 


\section{Una propuesta metodológica: la "hermenéutica profunda" como pers- pectiva comunicacional}

Metodológicamente, proponemos estudiar la activación digital desde la hermenéutica profunda (Thompson, 2002). Antes, sin embargo, citamos a Fuentes Navarro (2008).

De esta manera, y desplazando el foco del análisis comunicativo de los medios y los mensajes, a los sujetos sociales y los procesos de producción de sentido, podrá abordarse el estudio de la comunicación como ejercicio práctico de la reflexividad comunicativa, que se propone como concepto central de la exploración sistemática de los usos de Internet para el desarrollo de una metodología comunicacional (p. 195).

Ese es precisamente nuestro propósito: el desarrollo de una metodología comunicacional para la activación digital. A este respecto, cabe señalar dos posicionamientos. El primero, y siguiendo a De Moragas (2011), es que los estudios sobre medios de comunicación siempre se han visto condicionados por la realidad social y comunicativa del contexto en el que se desarrollan. Se puede y se debe estudiar a los medios, y en general a la comunicación, no como un fin en sí mismo, sino como condición para poder interpretar a la sociedad. En tal sentido, la comunicación es un objeto transversal, es un objeto-campo de estudio en cuyo análisis pueden confluir métodos y puntos de vista aportados por las distintas ciencias sociales y humanidades.

Figura 2: Enfoque tripartito de la activación digital.

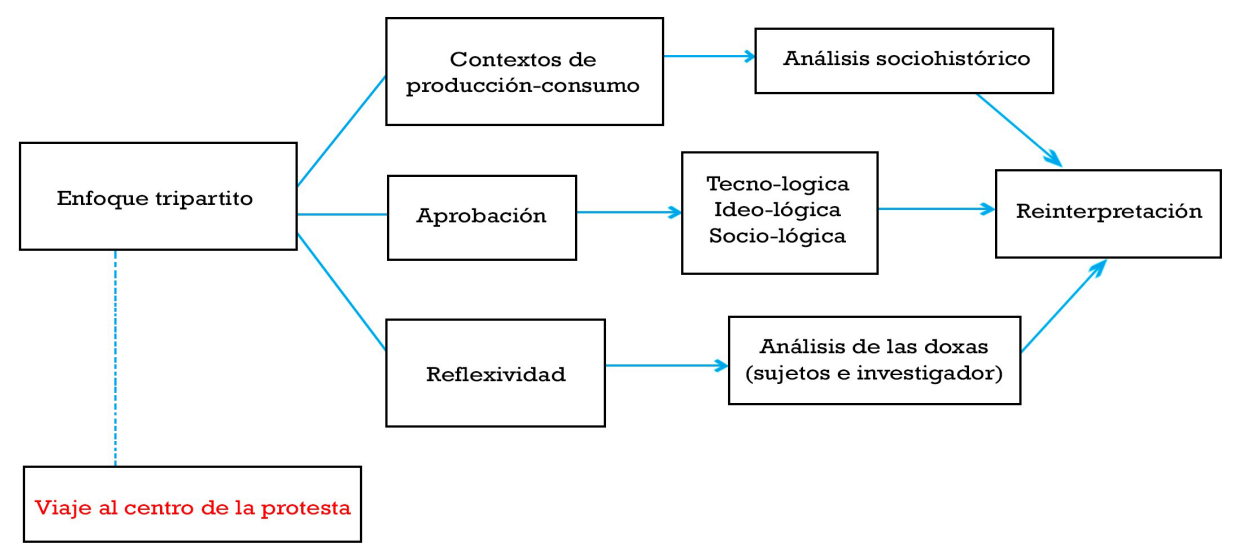

Fuente: Elaboración propia, basado en Thompson (2002). 
El segundo posicionamiento es el siguiente: si tal es el desafío que nos proponemos, a la teoría de la comunicación le corresponde una tarea interdisciplinar que ha de combinar conocimientos de diversas disciplinas en beneficio de la comprensión de la complejidad de su objeto específico. Interdisciplinariedad que, además, conecta con el propósito del programa académico dentro del que se desarrolló nuestra investigación de referencia.

Señalados estos posicionamientos, regresemos al desarrollo de una metodología comunicacional. Adoptaremos (y adaptaremos) el enfoque tripartito de la hermenéutica profunda (figura 2) propuesto por Thompson (2002). Esta propuesta se inscribe en una concepción estructural de cultura que enfatiza la "conformación significativa y la contextualización" de las formas simbólicas en espacios sociales estructurados. Asimismo, se inscribe en un doble análisis: cultural e ideológico. Mientras el primero corresponde al estudio de la estructura significativa y la contextualización social de las formas simbólicas, en este caso la activación digital, el segundo interpreta la relación entre significado y poder.

El enfoque consta de los siguientes análisis: a) sociohistórico, b) formal y c) de interpretación/reinterpretación. Antes que de etapas sucesivas, se trata de ámbitos analíticamente distintos de un proceso (re)interpretativo. El análisis sociohistórico consiste en reconstruir las condiciones estructurales y los contextos históricos, institucionales y tecnológicos de los productos comunicativos y los sujetos que los consumen y producen. De ahí que en nuestro caso refiramos a contextos de producción/consumo por tratarse los sujetos de la activación digital de prosumidores ${ }^{10}$. El análisis formal se convierte en el "análisis de la apropiación de las tres dimensiones" de la activación digital: tecnológica, ideológica y sociológica. Dos razones justifican la integración de los análisis señalados hasta ahora: a) eludir la falacia del reduccionismo, que nos remitiría únicamente al análisis sociohistórico y b) eludir la falacia del internalismo, quedándonos únicamente en el análisis formal de las prácticas comunicativas.

Mediante la interpretación/reinterpretación, se propone el análisis de una "doble reflexividad", tanto la del propio investigador como la de los sujetos. Lo

10. Prosumidor es un concepto acuñado por Alvin Toffler en La tercera ola, pero con antecedentes en la obra de Marshall McLuhan y Barrington Nevitt, Take Today. The executive as dropout, de 1972 (Islas, 2008). 
notable aquí es que en las reinterpretaciones provistas por el investigador o "doble hermenéutica" (Giddens, 1986) radica un potencial crítico de autorreflexividad para los sujetos respecto a sus propias prácticas comunicativas. De este modo, la adaptación de la hermenéutica profunda a nuestro objeto de estudio la metaforizamos como un "viaje al centro de la protesta" consta de las siguientes etapas en las que desdoblamos los contextos y dimensiones de la activación digital y señalamos diferentes productos analíticos.

En primer lugar, el análisis sociohistórico se divide en dos fases: los malestares de la globalización y las condiciones estructurales para la formación de figuras de subjetividad que confluyen en un tipo particular de sujeto político. Una segunda fase remite al movimiento social en diferentes momentos de emergencia. Aquí la hipótesis es que el movimiento social actúa como un mediador evanescente (Arditi, 2012) en el siguiente sentido: es tanto portador de culturas políticas que van evolucionando con el tiempo, así como también es un "médium", esto es, un ecosistema comunicativo.

En segundo lugar, desarrollamos el "análisis de la apropiación" de las tres dimensiones de la activación digital que se articulan como poder de la comunicación. Respecto a la tecno-lógica, nos concentramos en tres productos analíticos. El primero de ellos es la constitución de un "nodo de comunicación" al interior de la protesta y en cómo este nodo desarrolla un "modo de producción cultural". Un segundo producto analítico es el "mapa de la activación digital”, basado en análisis de contenidos (Schrøder, 2011) de un medio de comunicación digital. Lo que nos proponemos es, a través de indicadores cuantitativos, visualizar cómo el nodo de comunicación va construyendo una "red de activación digital" en el marco del movimiento social, la sociedad nacional y, eventualmente, el mundo. Un tercer producto es la definición de "usos sociales", en tanto expresiones de la articulación de las prácticas comunicativas con los contextos de la protesta y la vida cotidiana.

Mediante el análisis de esta primera dimensión de la apropiación, proponemos que el poder tecnológico significa una subversión de la lógica mercantil

11. Metáfora viajera de acuerdo con dos criterios: a) profundidad en el análisis y b) implicación del investigador con el objeto de estudio. 
de la producción cultural dominante, mediante el ejercicio de un modo de producción al margen del interés en el lucro y que se orienta por usos sociales basados en las culturas políticas y los fines de la protesta.

El poder ideo-lógico, segunda dimensión de las prácticas comunicativas, refiere a la producción de una narrativa política y una cultura visual propias que configuran una "partición de lo sensible", una ruptura en el régimen perceptual hegemonizado por la lógica espectacular de la política mediática. Cinco productos analíticos distinguen a esta dimensión. El primero de ellos es la delimitación de un "ciclo de activación digital", una temporalidad construida por el movimiento social y correspondiente al periodo de movilizaciones. Un segundo producto es el establecimiento de determinados "actores de la narrativa" y sus relaciones en función de las lógicas que encarnan ${ }^{12}$. Un tercer producto es la formación de una "comunidad global de resistencias", tributaria de diversas fuentes de internacionalización del movimiento que le otorga alcance y resonancia en todo el mundo. Un cuarto producto es la "transmedialidad" (Jenkins, 2008) de la narrativa política, esto es, su capacidad para circular por todos los medios disponibles y fomentar una cultura de la participación ${ }^{13}$. Finalmente, un quinto producto analítico remite a la "estética", aquella partición de lo sensible, la capacidad de reconfiguración perceptual y de volver visible, decible y pensable lo excluido por el orden policial.

El poder socio-lógico de la activación digital, por su parte, permite al movimiento estudiantil, como nunca antes en su historia de emergencias, la participación e incidencia en los sistemas de comunicación pública. Definimos aquí tres productos analíticos. En primer lugar, las "tácticas", definidas como astucias en la interacción, formas de resistir frente a adversarios dominantes y de persuadir a las audiencias. Reconocemos las siguientes: marchas, flashmobs, apoyo de líderes de opinión, sátira política y "funas" o scratches.

En segundo lugar, los "circuitos" que corresponden a contraflujos de información circulantes en las redes multimedia globales. Causa y efecto de estos circuitos es lo argumentado antes: la activación digital participa de los sistemas

12. Para lo cual utilizamos el "modelo actancial" de Greimas (Blanco \& Bueno, 1980).

13. A este respecto, nosotros adaptamos la definición de Jenkins (2008): una narrativa que se desarrolla a través de múltiples plataformas mediáticas y que cada nuevo texto hace una contribución específica y valiosa a la totalidad, estimulando la participación. 
de comunicación pública, del ecosistema comunicativo local/global. Dentro de ellos se ubican también la identificación de sus regiones de interacción comunicativas y dinámicas de circulación y la formación de esferas públicas transitorias como resultado de la combinación de tácticas y circuitos, de espacio material y digital de la protesta. Por último, nos preguntamos por el desarrollo de una "agenda de poder" (Dorantes, 2008) por parte de los estudiantes. Una combinación de agendas mediáticas, agendas políticas y agendas públicas que expresen los impactos en términos de una eventual "reprogramación" de la sociedad chilena.

El análisis de la reflexividad (momento importante de la hermenéutica profunda) se orienta a capturar tanto la "conciencia teórica" (Giddens, 1986) de los sujetos, así como la reflexividad del investigador en el trabajo de campo donde se construye una relación comunicativa (Lopes, 2010). Para el caso del investigador, esta se traduce en una serie de crónicas producidas durante el trabajo de campo y retrabajadas posteriormente. Para el caso de los sujetos, la reflexividad se nutre de la etnografía digital (Hine, 2000) y entrevistas en profundidad.

\section{La activación digital como modalidad de comunicación política}

Nuestra hipótesis (tanto de la investigación de referencia como en la propuesta que aquí desarrollamos) es que la activación digital puede ser postulada como una modalidad de comunicación política desarrollada por los sujetos en un entorno comunicativo marcado por convergencias y divergencias sociales, y ya no como prácticas periféricas al margen de los flujos y circuitos de la comunicación pública. Hacer eso, sin embargo, requiere problematizar los conceptos de política y de comunicación, pero sobre todo requiere analizar sus articulaciones en el contexto de la mediatización social contemporánea en torno a la acción colectiva de los movimientos e insurgencias, como ya se viene haciendo en algunos espacios académicos ${ }^{14}$.

Ante este desafío, logramos visualizar tres afluentes que podíamos encauzar

14. En espacios académicos como el mexicano o el anglosajón, se viene proponiendo incorporar a la comunicación política tanto los escenarios de comunicación de los movimientos sociales como los procesos de comunicación trasnacionales promovidos por las redes digitales interactivas (Pareja \& Molina, 2011; Wojcieszak, 2012). 
hacia la activación digital como objeto de estudio: la teoría política, los estudios culturales y la tradición de estudios sobre medios. Cabe, desde ya, una aclaración: nos referimos a la tradición de estudios sobre medios por cuanto utilizamos conceptos tomados desde diferentes perspectivas ("economía política de la comunicación", “ecología de medios”, "Mass Communication Research") en función de las demandas del objeto de estudio, que es además un objeto emergente y que está desafiando las antiguas aprehensiones epistemológicas entre las diferentes perspectivas ${ }^{15}$.

Parte de la complejidad de la activación digital fue que nos enfrentó, en el análisis de la Apropiación que ya revisamos, con un proceso de producción/ consumo derivado de la condición de prosumidores de los sujetos que comprendía la totalidad del modelo canónico de la comunicación: emisión-mensajes-recepción. Este hecho, por lo tanto, nos llevó a la adaptación de la propuesta del modelo tripartito de Thompson (2002) y a la necesidad de recurrir a conceptos tomados de estas tres fases del proceso comunicativo dispensadas por las teorías de la comunicación.

Aclarado lo anterior, comencemos por la política. Lo que Rancière (1996) ofrece, a nuestro parecer, es fugar la política más allá del subsistema de intercambio institucionalizado del conflicto político que, para el autor, sólo es una parte más del orden policial. O, en palabras de Arditi (2010), ubicar la política por fuera del paradigma liberal democrático clásico. Gracias a esto, el sujeto político se desanuda de una función social predeterminada o de un lugar específico dentro de la estructura social (Muñoz, 2006). Ubicuidad de la política, entonces, que resulta fundamental para la activación digital.

Asimismo, Rancière (2003) nos ofrece otro supuesto: el de la igualdad radical, aquella donde "todas las frases, y por consecuencia todas las inteligencias que las producen, son de la misma naturaleza" (p. 10). A partir de estos supuestos, se derivan otras tres comprensiones. La primera es que la democracia no es una cuestión de régimen institucional, sino de política. Todo régimen político es en rigor un orden policial que asigna posiciones fijas a los sujetos,

15. Véase a este respecto lo señalado por Garnham (2006) a propósito de la "incompatibilidad" entre los estudios culturales y la economía política de la comunicación; o los desafíos a la investigación en comunicación en el nuevo contexto de "convergencia de medios" (Jensen, 2010). 
modos de hacer, de decir y de pensar. La democracia, en cambio, no es un arkhe, en tanto principio de gobierno excluyente, sino más bien un kratos, es la igualdad como principio de gobierno (Rancière, 1996).

La segunda comprensión es que (pese a su ubicuidad potencial) no todo es política, sino más bien aquella acción que da lugar al encuentro de la lógica policial y la lógica igualitaria. Es la confrontación del desacuerdo ante el orden policial. Una confrontación que no es tanto argumentada como desplegada socialmente, que es performativa. No es tanto una victimización como el reconocimiento de una igualdad cuya falta de reconocimiento es puesta en evidencia (Rancière, 1996). De este modo, la igualdad desplegada es resultado de una producción colectiva, de un proceso constituyente al interior del demos. La igualdad es creada "por" el pueblo antes que "para" el pueblo, invirtiendo así la lógica representativa del régimen democrático, por una lógica participativa de la política democrática.

La tercera comprensión que nos ofrece Rancière (1996) es que la política democrática lleva a cabo una partición de lo sensible, estimula una participación estética expresada en la reconfiguración de la disposición perceptual de lo visible, lo decible y lo pensable (o imaginable) para una sociedad en tanto comunidad política.

¿Cómo evaluar entonces los resultados de la política democrática? En primer lugar, no puede ser medida por sus resultados, por el éxito o fracaso de sus objetivos. Una política democrática no se mide en función de elementos externos por fuera de la acción del "demos", sino por el proceso de subjetivación que ocurre en su interior. Esto nos remite a otro aporte, esta vez de Arditi (2012): las insurgencias y movimientos sociales contemporáneos actúan como mediadores evanescentes, es decir, que de un lado no desaparecen pues siempre dejan un rastro y que, de otro lado, representan "pasajes" hacia lo que está por venir.

Dejamos hasta aquí las comprensiones de la política democrática que nos ofrece Rancière (1996) para pasar a las de la comunicación y señalar que lo que aquí nos proponemos es ofrecer una perspectiva sociocultural de la comunicación, así definida por Fuentes Navarro (2008):

una especie de proyecto de "estilo de pensamiento", fundamentalmente heurístico, orientado más por las búsquedas que por los hallazgos y que, cen- 
trado en la construcción comunicativa de las intersubjetividades, trata de no desintegrar de ese "centro" las condiciones históricas y estructurales que lo determinan, en especial el poder, en todas sus dimensiones. (pp. 9-10).

Lo que nos aportan los estudios culturales, en este sentido, son desplazamientos similares a los de Rancière (1996) en cuanto a la política: de un lado, "fugarse" de la comprensión habitual de los procesos comunicacionales de tipo transmisivos (Carey, 1989) o lineales; de otro lado, incorporar como principio de igualdad la producción intersubjetiva de significados compartidos.

Asimismo, los estudios culturales nos aportan una comprensión del eje cultura-ideología-hegemonía, fundamental para la activación digital como modalidad de comunicación política. En cuanto a la cultura, el propósito que justifica a los estudios culturales ha sido revocar los privilegios de "la cultura con C mayúscula" y reivindicar los significados y valores de la mayoría subordinada como elementos centrales de un posible orden alternativo (Fuentes Navarro, 2008). Una cultura que, para las prácticas comunicativas de la activación digital, se expresa en formas simbólicas histórica y socialmente estructuradas (Thompson, 2002) y que demandan un análisis en estos términos. Una cultura, también, actualmente de matriz híbrida, interpenetración de modernidad/posmodernidad y convivencia de modelos de acumulación fordista y flexible (Harvey, 1998).

Del lado de la ideología (pese a la crisis de las grandes narrativas denunciada por el posmodernismo, así como la acción colectiva poshegemónica que caracteriza a los movimientos sociales en red), esta adquiere en la activación digital una renovada pertinencia: la de subvertir las lógicas de dominación incorporadas en los flujos de las redes multimedia globales y que tienen en la política mediática, en tanto modalidad dominante de la comunicación política, la expresión del orden policial. Esta lógica, además, se extiende a la producción cultural y la creciente importancia económica de las industrias creativas (OIC, 2008).

En cuanto a la hegemonía, definida por Gramsci (2006) como dominación y construcción del consenso, esta constituye un sentido de realidad para las personas. Corresponde a un sistema de prácticas, valores y significados que no son meramente abstractos, sino que organizan la vida cotidiana (Williams, 2000). El "poder en todas sus dimensiones", agrega Fuentes Navarro (2008), es indisociable del significado en la perspectiva sociocultural de la comunicación que, 
de tal modo, se vuelve necesariamente "política". Sin embargo, el poder dentro del nuevo ambiente mediático es disputado fundamentalmente en las redes multimedia globales y en circuitos que abarcan desde la esfera pública en reconfiguración hasta el enmarcamiento mental de las personas (Castells, 2009).

Rescatamos también de la tradición comunicacional el concepto de mediatización en una de sus vertientes más afines al análisis sociocultural. Para Hjarvard (2008), por mediatización se asume el proceso mediante el cual la sociedad se torna dependiente de los medios y su lógica. Un proceso caracterizado por una dualidad en la cual los medios de comunicación pasaron de estar integrados al funcionamiento de otras instituciones a adquirir el status de instituciones sociales autónomas.

Los medios de comunicación han dejado de ser organizaciones o recursos instrumentales en la sociedad para volverse "constructores" de la misma al ubicarse en los diferentes intersticios de las interacciones sociales. La dualidad de esta relación estructural impacta en cómo los mensajes mediáticos, en contextos sociales específicos, son apropiados y percibidos por emisores y receptores, impactando sobre las relaciones sociales.

Por "lógica de los medios", se refiere al modus operandi institucional, estético y tecnológico de los medios. La lógica mediática influye la forma que la comunicación adquiere como, por ejemplo, en las narrativas políticas. Esta lógica influye la naturaleza y la función de los sistemas de comunicación. El grado de dependencia hacia los medios de comunicación, sin embargo, varía socialmente (Hjarvard, 2008).

La premisa aquí es que la sociedad contemporánea está permeada por los medios de comunicación de una manera tal que no pueden ser separados del funcionamiento de las instituciones culturales y sociales. De ahí el interés en conocer cómo estas instituciones y procesos se han ido modificando en función del nuevo entorno mediático (Press \& Williams, 2010).

Winfried Schulz (citado en Mazzoleni, 2008; Lundby, 2009; Hjarvard, 2008) identifica cuatro procesos donde los medios alteran la comunicación y la interacción humanas. En primer lugar, ellos extienden las posibilidades de comunicación en tiempo y espacio; en segundo lugar, sustituyen determinadas actividades sociales e instituciones con las que nos relacionábamos presen- 
cialmente; en tercer lugar, los medios permiten una fusión o amalgama de actividades, la convivencia de comunicación personal y comunicación mediada, así como su "infiltración" en la vida cotidiana; en cuarto lugar, los sujetos y las instituciones desarrollan una adaptación de su comportamiento a las valoraciones, los formatos y las rutinas de los medios de comunicación.

Retomamos, por último, lo señalado al inicio de esta sección. Históricamente, la comunicación política, que ha sido fundamental en la constitución teórica del campo de la comunicación ${ }^{16}$, ha tendido a mirar la relación gobernantes/ gobernados desde la óptica de los primeros y se ha centrado en el análisis de procesos electorales y de actores institucionalizados (Bonilla, 2004). La teoría de la activación digital, en cambio, plantea el reto de visualizar las lógicas del contrapoder, las disputas a la hegemonía que provienen de parte de los gobernados, como por ejemplo los movimientos sociales que participan actualmente en los sistemas de comunicación pública y del nuevo espacio público en reconfiguración.

Es así (a través de una inversión de las lógicas para la comprensión habitual de la política y la comunicación) como sustentamos teóricamente nuestra hipótesis y concluimos el desarrollo de nuestra propuesta.

\section{Fuentes consultadas}

Acosta, R. (2009). La política viral es articularse con personas desconocidas y realizar una acción alternativa. Entrevista con Benjamín Arditi, experto en teoría política. Revista Magis, 412, pp. 12-18. Recuperado de https://magis.iteso.mx/sites/default/files/412\%20magis\%20web.pdf

Alonso, J. (2012). Cavilaciones sobre movilizaciones de indignados sociales. Recuperado de http://issuu.com/albedrio/docs/cavilacionessobreindignadosalonso

16. Pensemos solamente en la creencia sobre los "medios todopoderosos", el paradigma de Lasswell o las teorías sobre los "efectos limitados", sin considerar los fundamentos mismos del estudio de la propaganda, para caer en la cuenta del valor constituyente de la comunicación política en el campo de la comunicación. 
Arditi, B. (2010). Posthegemonía: la política fuera del paradigma postmarxista habitual. En H. Cairo \& J. Franzé (Eds.), Politica y cultura (pp. 159-193). Madrid: Biblioteca Nueva.

Arditi, B. (2012). Insurgencies don't have a plan - they are the plan. Political performatives and vanishing mediators in 2011. JOMEC Journal. Journalism, Media and Cultural Studies, 1. doi: 10.18573/j.2012.10218

Arquilla, J. \& Ronfeldt, D. (2001). Networks and netwars: the future of terror, crime and militancy. Rand Corporation. Recuperado de http://www. rand.org/pubs/monograph_reports/MR1382.html

Asociación Latinoamericana de Información, ALAI (2001). Movimientos sociales en la red. Recuperado de http://alainet.org/publica/msred/

Asociación Latinoamericana de Información, ALAI (2005). Movimientos sociales y comunicación. Recuperado de http://alainet.org/publica/movcom/mov_soc_com.pdf

Baldi, S. (2000). The Internet for international political and social protest. Recuperado de http://baldi.diplomacy.edu/articles/protest2. htm\#ref

Barandiaran, X. (2003). Activismo digital y telemático. Poder y contrapoder en el ciberespacio. Recuperado de http://www.sindominio.net/

Bennett, L. (2003). Communicating global activism. Information, Communication \& Society, 6(2), 143-168.

Berman, M. (2004). Todo lo sólido se desvanece en el aire. La experiencia de la modernidad. México, DF: Siglo XXI.

Bey, H. (1991). La zona temporalmemte autónoma. Recuperado de http:// lahaine.org/pensamiento/bey_taz.pdf

Blanco, D. \& Bueno, R. (1980). Metodología del análisis semiótico. Lima: Universidad de Lima. 
Bonilla, J. (2004). Revisitando el concepto de comunicación política. Apuntes para una discusión. Ponencia en VIII Congreso ALAIC, La Plata, Argentina. Recuperado de http://www.alaic.net/VII_congreso/gt/gt_3/ GT3-3.html

Bustamante, O. (2014). Mediatización de la protesta: la activación digital como modalidad de comunicación política. Viaje al centro del movimiento estudiantil 2011 en Chile (tesis doctoral). Instituto Tecnológico y de Estudios Superiores de Occidente, Jalisco, México.

Candón Mena, J. (2010). Internet en movimiento. Nuevos movimientos sociales y nuevos medios en la sociedad de la información (tesis doctoral). Universidad Complutense de Madrid, España.

Carey, J. (1989). Communication as Culture. Essays on Media and Society. Nueva York: Routledge.

Castells, M. (2003). La galaxia Internet. Nueva York: Random House.

Castells, M. (2009). Communication Power. Nueva York: Oxford University Press.

Castells, M. (2012). Networks of outrage and hope. Social movements in the Internet age. Cambridge: Polity Press.

Chihu Amparán, A. (2006). El análisis de los marcos en la sociología de los movimientos sociales. México, DF: Conacyt, UAM-Iztapalapa.

Crilley, K. (2001). Information warfare: new battlefields terrorists, propaganda and the Internet. Aslib Proceeding, 53(7), 250-264.

Critical Art Ensamble, CAE (2001). Digital Resistance. Recuperado de http:// www.critical-art.net/books/digital

De Certeau, M. (2000). La invención de lo cotidiano. I. Artes de hacer. México, DF: Universidad Iberoamericana, ITESO. Recuperado de https:/circulosemiotico.files.wordpress.com/2012/10/de-certeau-michel-la-invencion-de-lo-cotidiano-1-artes-de-hacer.pdf 
Della Porta, D. \& Diani, M. (2006). Social movements. An introduction. Oxford: Blackwell.

De Lucca, K. \& Peeples, J. (2002). From public sphere to public screen: democracy, activism and the "violence" of Seattle, Critical studies in Media Communication, 19(2), pp.125-151.

De Moraes, D. (2001). O ativismo digital. Recuperado de http://www.bocc. ubi.pt/pag/moraes-denis-ativismo-digital.html

De Moragas, M. (2011). Interpretar la comunicación. Estudios sobre medios en América y Europa. Barcelona: Gedisa.

Dorantes, G. (2008). La construcción de la agenda de poder. Revista Mexicana de Ciencias Políticas y Sociales, L(204), pp. 77-99. Recuperado de http://redalyc.uaemex.mx/pdf/421/42112044006.pdf

Fuentes Navarro, R. (2008). La comunicación desde una perspectiva sociocultural. Acercamientos y provocaciones 1997-2007. México, DF: ITESO de Guadalajara.

Fleischman, L. (2004). Internet y movimientos sociales: comunicación en los movimientos de resistencia global. IAMCR Conference Section: Participatory Communication Research.

Garnham, N. (2006). Contribution to a political economy of mass-communication. En D. Kellner \& M. Durham (Eds.), Media and cultural studies: keyworks (pp. 201-229). Oxford: Blackwell.

Garrett, K. (2006). Protest in an Information Society: A Review of Literature on Social Movements and New ICTs. Communication and Society, 9(2), 202-224. Recuperado de http:// journalsonline.tandf.co.uk/openurl.asp?genre=article\&id=doi:10.1080/13691180600630773

Giddens, A. (1986). The constitution of society. Outline of the Theory of Structuration. California: University of California Press. 
Gramsci, A. (2006). (i) History of the subaltern classes; (ii) The concept of ideology; (iii) Cultural themes: ideological material. En D. Kellner \& M. Durham (Eds.), Media and cultural studies: keyworks (pp. 13-16). Oxford: Blackwell.

Hardt, M. \& Negri, A. (2004). Multitud. Guerra y democracia en la era del imperio. Madrid: Debate.

Hardt, M. \& Negri, A. (2009). Commonwealth. Boston: Harvard University Press

Harvey, D. (1998). La condición de la posmodernidad. Investigación sobre los orígenes del cambio cultural. Buenos Aires: Amorrortu.

Himanen, P. (2002). La ética del hacker y el espíritu de la era de la información. Barcelona: Destino.

Hine, C. (2000). Virtual Etnography. Londres: Sage.

Hjarvard, S. (2008). The Mediatization of Society. A Theory of the Media as Agents of Social and Cultural Change. Nordicom Review, 29(2), 105-134.

Islas, O. (2008). El prosumidor: el actor comunicativo de la sociedad de la ubicuidad. Palabra Clave, 11(1), 29-39.

Jensen, K. (2005). Interface://Culture. The world wide web as political resource and aesthetic form. Frederiksberg: Samfundslitteratur.

Jensen, K. (2010). Media Convergence. The three degrees of network, mass and interpersonal communication. Londres: Routledge.

Jensen, K. (2013). Definitive and sensitizing conceptualizations of mediatization. Communication Theory, 23, 203-222.

Jenkins, H. (2008). Convergence Culture: la cultura de la convergencia de los medios de comunicación. Barcelona: Paidós. 
Joyce, M. (Ed.) (2010). Digital activism decoded. The new mechanics of change. Nueva York: International Debate Education Association.

Kahn, R. \& Kellner, D. (2004). New media and Internet activism: from the "battle of Seattle" to blogging. New Media and Society, 6(1), 87-95.

Kavada, A. (2006). Exploring the role of the Internet in the "movement for alternative globalization”. The case of the Paris 2003 European Social Forum. Paper to be presented in the 56th Political Studies Association Conference.

Lago, S. (2006). La intervención política de los movimientos sociales en la sociedad de la información. UNIrevista, 1(3). Recuperado de http:// www.razonypalabra.org.mx/anteriores/n52/39Lago.pdf

Lago, S. \& Jara, A. (2001). Nuevos interrogantes sobre los movimientos sociales antiglobalización: de Seattle a Porto Alegre. Ponencia en la Conferencia regional para América Latina y El Caribe. Asociación Internacional de Sociología. Caracas, Venezuela.

Lago, S. \& Marotias, A. (2007). Los movimientos sociales en la era de Internet. Razón y palabra, 54. Recuperado de http://www.razonypalabra. org.mx/anteriores/n54/lagomarotias.html

Laraña, E. (1999). La construcción de los movimientos sociales. Madrid: Alianza.

Leetoy, S. (2004). La guerra ideológica en el ciberespacio: la conformación de redes sociales en Internet como estrategia de propaganda en el conflicto Zapatista en Chiapas. Reunión 2004 de la Asociación de Estudios Latinoamericanos (Latin American Studies Association, LASA), Las Vegas, Estados Unidos.

Lopes, M. (2010). Reflexividade e relacionismo como questões epistemológicas na pesquisa empírica em comunicação. Ponencia presentada en el X congreso de la ALAIC, Bogotá, Colombia. 
Lull, J. (1980). Los usos sociales de la televisión. Human Communication Research, 6, 197-209. Recuperado de http://www.jameslull.com/losusos.html

Lundby, K. (2009). Introduction: “Mediatization” as key. En K. Lundby (Ed.), Mediatization: concept, changes, consequences (pp. 1-20). Nueva York: Peter Lang Publishing.

Mardones, J. (1996). Los nuevos movimientos sociales y la sociedad moderna. En J. Mardones (Dir.), 10 palabras claves sobre movimientos sociales (pp. 13-44). Navarra: Verbo Divino.

Mari Sáez, V. (2007). Contra la evaporación de la dimensión política de la comunicación. Movimientos sociales, ONG y usos de Internet. ZER, 22, 453-471.

Marí Sáez, V. \& Sierra Caballero, F. (2008). Capital informacional y apropiación social de las nuevas tecnologías. Las redes críticas de empoderamiento local en la Sociedad Europea de la Información. Telos, 74. Recuperado de http://sociedadinformacion.fundacion.telefonica.com/ telos/articulodocumento.asp@idarticulo=2\&rev=74.htm

Martín-Barbero, J. (2002). Tecnicidades, identidades, alteridades: des-ubicaciones y opacidades de la comunicación en el nuevo siglo. Diálogos de la comunicación, 64, 8-23.

Mazzoleni, G. (2008). Mediatization of society. En W. Donsbach (Ed.), The International Encyclopedia of Communication. Vol. VII. Oxford: Blackwell Publishing.

McAdam, D., McCarthy, J. \& Zald, M. (Eds.) (1999). Movimientos sociales. Perspectivas comparadas. Madrid: Istmo.

Melucci, A. (1999). Acción colectiva, vida cotidiana y democracia. México, DF: COLMEX, Centro de Estudios Sociológicos.

Monasterios, G. (2001). Aproximaciones al movimiento indigena en Internet. Ponencia en el XXIII Congreso Internacional de la Latin America Studies Association, Washington DC, Estados Unidos. 
Monasterios, G. (2003). Abya Yala en Internet: políticas comunicativas y representaciones de identidad de organizaciones indígenas en el ciberespacio. En D. Mato (Coord.), Políticas de identidades y diferencias sociales en tiempos de globalización (303-330). Caracas, FACES, UCV.

Muñoz, M. (2006). Laclau y Rancière: algunas coordenadas para la lectura de lo político. Andamios, 2(4), 119-144. Recuperado de http://www. redalyc.org/articulo.oa? $\mathrm{id}=62820405$

Observatorio de Industrias Creativas, OIC (2008). La economía creativa de la ciudad de Buenos Aires. Buenos Aires: Ministerio de Desarrollo Económico, Gobierno de Buenos Aires.

Pareja, N. \& Molina, S. (Coords.) (2011). Comunicación política en México. México, DF: UNAM.

Pasquinelli, M. (2002). Mediactivismo. Activismo en los medios. Estrategias y prácticas de la comunicación independiente. Roma: Derive Approdi. Recuperado de http://es.scribd.com/doc/146196876/Mediactivismo-Pasquinelli-2002

Press, A. \& Williams, B. (2010). The new media environment. An introduction. Nueva Jersey: Willey-Blackwell.

Ramírez, J. (2006). Ciudadanía mundial. México, DF: ITESO, Universidad Iberoamericana.

Rancière, J. (1996). El desacuerdo. Política y filosofia. Buenos Aires: Nueva Visión.

Rancière, J. (2003). El maestro ignorante. Cinco lecciones sobre la emancipación intelectual. Barcelona: Laertes.

Rheingold, H. (2004). Multitudes inteligentes. Barcelona: Gedisa.

Rodríguez Arechavaleta, C. (2010). De la estructura de oportunidades políticas a las identidades colectivas. Apuntes teóricos sobre el poder, la acción colectiva y los movimientos sociales. Espacios Públicos, 13(27), 187-215. 
Schrøder, K. (2011). Discursive realities. En K. Jensen (Ed.), Handbook of media and communication research. Qualitative and quantitative methodologies (pp.106-130). Londres: Routledge.

Scolari, C. (2008). Hipermediaciones. Elementos para una teoría de la comunicación digital interactiva. Barcelona: Gedisa.

Snow, D., Rochford, B., Worden, S. \& Benford, R. (2006). Procesos de alineamiento de marcos, micromovilización y participación en movimientos. En C. Amparan (Coord.), Análisis de los marcos en la sociología de los movimientos sociales (pp. 31-82). México DF: Conacyt-UAM Iztaplapa.

Sunkel, G., Trucco, D. \& Möller, S. (2011). Aprender y enseñar con las tecnologías de la información y las comunicaciones en América Latina: potenciales beneficios. Recuperado de https://repositorio.cepal.org/ bitstream/handle/11362/6177/1/S2011902_es.pdf

Tarrow, S. (2004). El poder en movimiento. Los movimientos sociales, la acción colectiva y la política. Madrid: Alianza.

Tilly, C. (2005). Los movimientos sociales entran en el siglo XXI. Política y Sociedad. 42(2), 11-35. Recuperado de https://revistas.ucm.es/index. php/POSO/article/view/POSO0505230011A/22873

Thompson, J. (2002). Ideología y Cultura Moderna. Teoría crítica social en la era de la comunicación de masas. México, DF: UAM Xochimilco.

Valderrama, C. (2010). Movimientos sociales. TIC y prácticas políticas. En R. Aparici (Coord.), Conectados en el ciberespacio (pp. 175-188). Madrid: Universidad Nacional de Educación a Distancia.

Williams, R. (2000). Marxismo y literatura. Barcelona: Península.

Wojcieszak, M. (2012). Trasnational communication symposium: challenges and opportunities for political communication research. International Journal of communication, 6, 255-265. 